\title{
Mixed Vascular Occlusion in a Patient with Interferon- Associated Retinopathy
}

\author{
Boris J. Bajaire $^{a}$ Diego F. Paipilla ${ }^{a}$ Cesar E. Arrieta ${ }^{b}$ \\ Elena Oudovitchenkoc \\ Departments of a Vitreous and Retina, and ${ }^{\mathrm{b}}$ Ophthalmology, San Martin University, \\ and 'Simon Bolívar Hospital, Bogota, Colombia
}

\section{Key Words}

Mixed vascular occlusion - Hepatitis C virus - Interferon-associated retinopathy

\begin{abstract}
Interferon (INF)-associated retinopathy occurs in 15-64\% of INF-treated patients, transforming this complication into a significant risk for visual impairment. This retinopathy has been described as an ocular complication with a variable clinical course, usually benign and asymptomatic. The most common findings are hemorrhages and cotton wool spots. Atypical ocular side effects include branch or central retinal artery occlusion, central retinal vein occlusion, anterior ischemic optic neuropathy, optic disc edema, neovascular glaucoma and vitreous hemorrhage. Some case series suggest that in most cases the clinical course of the disease is benign, asymptomatic and without long-term consequences and therefore do not recommend any specific treatment; they only recommend the discontinuation of INF in patients with severe manifestations or risk factors such as hypertension or diabetes mellitus. The case reported here presents an atypical manifestation of INF-associated retinopathy consisting of a mixed retinal vascular occlusion (arterial and venous), associated with severe occlusive inflammatory microangiopathy with extensive retinal damage by ischemia and a torpid clinical course despite suspension of treatment. These varieties of occlusive vascular events have not yet been found simultaneously in the literature and neither with an unfavorable clinical course. Although the clinical course of INF-associated retinopathy in most cases is asymptomatic, there may be complications with risk to vision, which is less common. The magnitude and severity of the consequences associated with INF therapy are to be determined in prospective further studies.
\end{abstract}




\section{Introduction}

Chronic infection with hepatitis $\mathrm{C}$ virus is estimated to affect almost 4 million people in the USA, 5 million in Europe, and 170 million worldwide [1]. Interferon (INF)associated retinopathy occurs in $15-64 \%$ of INF-treated patients [2, 7], transforming this complication into a significant risk factor for visual impairment.

Pegylated INF (peg-INF) is a complex of proteins with antiviral, antiproliferative and immunomodulatory activity, which is used in combination with ribavirin for the treatment of chronic hepatitis $\mathrm{C}$ in adult patients $[5,6]$. INF-associated retinopathy has been reported as an ocular complication with variable clinical course, which is usually benign and asymptomatic $[3,4]$. We report an unusual case of unilateral INF-associated retinopathy in a patient who presented with a mixed retinal vascular occlusion connected with severe visual impairment.

\section{Case Report}

A 45-year-old female, treated for 4 months with peg-INF $\alpha 2$ a (180 $\mu$ g weekly) and ribavirin $(1,000$ $\mathrm{mg}$ daily) for hepatitis $\mathrm{C}$ and diagnosed 1 year previously, presented with sudden painless visual loss in the left eye. Her general health did not show any other alterations. The presence of diabetes, hypertension and other risk factors (cardiovascular or systemic) was ruled out by an Internal Medicine doctor. Ocular examination showed visual acuity of 20/20 in the right eye and counting fingers in the left eye. The anterior segment did not show any alteration. Intraocular pressure in the right eye was 13 and in the left eye 8 . Fundoscopy in the right eye was normal. The left eye revealed retinal vessel tortuosity, multiple flame hemorrhages at the posterior pole, cotton wool spots and superior temporal retinal pallor. Fluorescein angiography revealed delayed arterial and venous filling, large areas of ischemia in the superior quadrants, retinal hemorrhages, periphlebitis, macular edema, upper trunk venous occlusion and lower trunk venous stasis associated with occlusion of the superior temporal arterial branch (fig. 1). Optical coherence tomography (OCT) showed macular thickening (626 $\mu \mathrm{m})$ secondary to diffuse edema and presence of microcysts (ig. 2).

INF and ribavirin were discontinued, and the patient was given 2 doses of intravitreal avastin injection with a 1-month interval. She presented with visual improvement in the left eye (20/60) and decreased macular retinal thickness $(322 \mu \mathrm{m})$ (fig. 3$)$. Four months later, she showed sudden visual loss in the left eye. Ocular examination revealed visual acuity of hand movement, superior peripapillary fibrovascular proliferation and retinal hemorrhages. Large areas without capillary perfusion in the upper quadrants, neovascularization and diffuse macular edema were found in the control

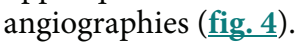

Although retinal photocoagulation was performed in the affected quadrant, 5 months later, tractional retinal detachment became apparent, which was treated with posterior vitrectomy. After 3 years of follow-up, best-corrected visual acuity in the left eye was 20/400, the anterior segment exhibited no changes, and fundoscopy showed optic disc pallor, superior retinal atrophy, and macular hole (fig. 5).

\section{Discussion}

Ocular side effects of treatment with INF and ribavirin for hepatitis $\mathrm{C}$ are well known. The most common findings are hemorrhages and cotton wool spots. Other findings are hyperemia of the disc and macular edema [3]. Atypical ocular side effects reported in connection with the use of INF include branch retinal artery occlusion, central retinal vein occlusion, Vogt-Koyanagi-Harada-like disease [5], anterior ischemic optic neuropathy $[5,9]$, retinal detachment, subconjunctival hemorrhage, optic disc edema, 
neovascular glaucoma, vitreous hemorrhage [10], panophthalmitis [4, 5], and central retinal artery occlusion [11]. The common denominator of these atypical severe manifestations of INF-associated retinopathy is complete and permanent visual loss despite discontinuation of treatment and proper ophthalmological management $[5,9]$.

Some case series suggest that in most patients, the clinical course of the disease is benign, asymptomatic, and without long-term consequences and therefore do not recommend any specific treatment; they only recommend the discontinuation of INF treatment in patients with severe manifestations or risk factors such as hypertension or diabetes mellitus $[3,6,7]$.

The exact pathophysiological mechanism due to which retinopathy develops is unknown. Similarities with some characteristics of diabetic and hypertensive retinopathy suggest an ischemic mechanism. Other authors suggest that immune complex deposits in the vessels lead to retinal capillary perfusion failure and the formation of cotton wool spots $[3,7]$. The increase in photocoagulated phospholipids in hepatitis $\mathrm{C}$ causes a hypercoagulable state when combined with INF- $\alpha$, inducing production of thrombogenic autoantibodies. Recent studies have found a linkage between INF-associated retinopathy and elevated serum levels of vascular endothelial growth factor (VEGF). The appearance of elevated VEGF levels is correlated with activation of angiogenesis, but its role in the pathogenesis of retinopathy is still unclear $[6,7]$.

The case reported here presents an atypical manifestation of INF-associated retinopathy consisting of a mixed retinal vascular occlusion (arterial and venous), associated with severe occlusive inflammatory microangiopathy with extensive retinal damage by ischemia and a torpid clinical course despite suspension of treatment. Case reports of this variety of occlusive vascular events have not yet been found in the literature, nor have such cases with an unfavorable clinical course been found, which challenge the generally accepted concept that retinopathy has a benign clinical course with a low risk of functional compromise and a self-limited course.

In the differential diagnosis, the presence of thrombotic or embolic retinal artery occlusion was considered. Assessment by an Internal Medicine doctor ruled out the presence of risk factors (cardiovascular and systemic) for this disease. The clinical presentation 16 weeks after initiation of INF therapy also contradicts this diagnostic possibility, since INF retinopathy can occur between 4 and 28 weeks after initiation of treatment, more frequently within the first 16 weeks (62\% of cases) [4].

It is also remarkable that the picture presented by this patient had other atypical features, such as the absence of associated systemic disorders (hypertension, diabetes), ocular involvement, and persistent unilateral retinopathy even 6 months after discontinuation of INF treatment. In our literature review, only one case of unilateral INF-associated retinopathy was reported [3].

An insufficient vascular growth may significantly impact the nervous system, and angiogenesis is directly correlated with survival in patients with stroke [13]. The initial improvement in clinical symptoms with the use of a VEGF inhibitor could be associated with a decrease in vascular permeability and the disappearance of macular edema, but retinal ischemia may have been worsened by early antiangiogenic therapy (Avastin ${ }^{\circledR}$ ). The retrospective analysis suggests that early photocoagulation of the ischemic bed during the initial treatment could be decisive in preventing retinal and disc neovascularization. 


\begin{tabular}{c|l|l|l}
$\begin{array}{c}\text { Case Reports in } \\
\text { Ophthalmology }\end{array}$ & $\begin{array}{l}\text { Case Rep Ophthalmol 2011;2:23-29 } \\
\text { DOI: 10.1159/000323942 }\end{array}$ & $\begin{array}{l}\text { Published online: } \\
\text { January 11, 2011 }\end{array}$ & $\begin{array}{l}\text { O 2011 S. Karger AG, Basel } \\
\text { ISSN 1663-2699 } \\
\text { www.karger.com/cop }\end{array}$ \\
\hline
\end{tabular}

Although the clinical course of INF-associated retinopathy is asymptomatic in most cases, there may be complications involving a risk for visual impairment, which is less common. However, the actual magnitude and severity of the consequences associated with INF therapy are to be determined in further prospective studies $[7,8]$.
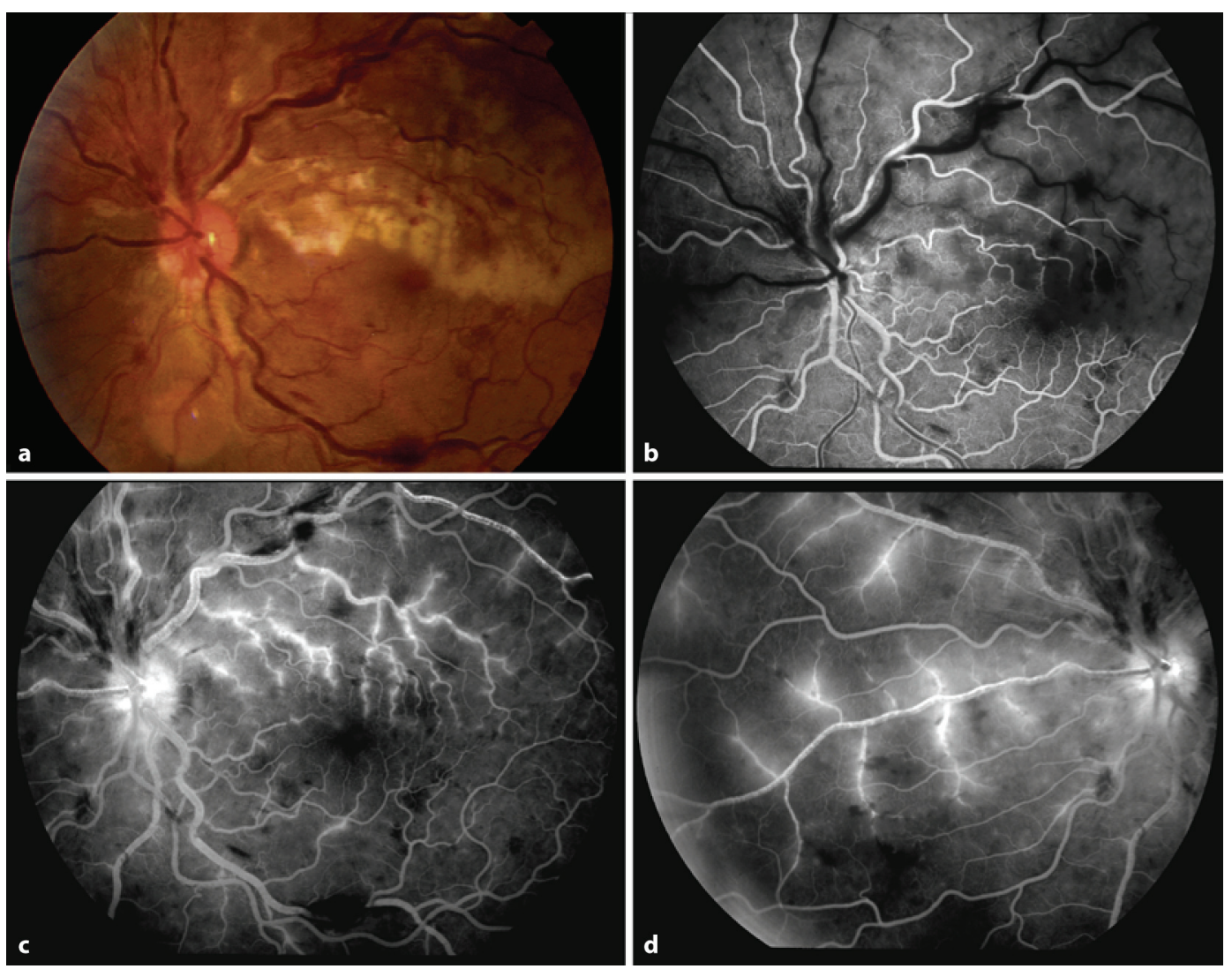

Fig. 1. Fluorescein angiogram $24.0 \mathrm{seg}, 3: 53$ and 8:32. Fluorescein angiography shows delayed arterial and venous filling, large areas of ischemia in the superior quadrants, retinal hemorrhages, periphlebitis, macular edema, upper trunk venous occlusion and lower trunk venous stasis associated with occlusion of the superior temporal arterial branch. 


\begin{tabular}{c|l|l|l}
$\begin{array}{c}\text { Case Reports in } \\
\text { Ophthalmology }\end{array}$ & $\begin{array}{l}\text { Case Rep Ophthalmol 2011;2:23-29 } \\
\text { DOI: 10.1159/000323942 }\end{array}$ & $\begin{array}{l}\text { Published online: } \\
\text { January 11, 2011 }\end{array}$ & $\begin{array}{l}\text { O 2011 S. Karger AG, Basel } \\
\text { ISSN 1663-2699 } \\
\text { www.karger.com/cop }\end{array}$ \\
\hline
\end{tabular}

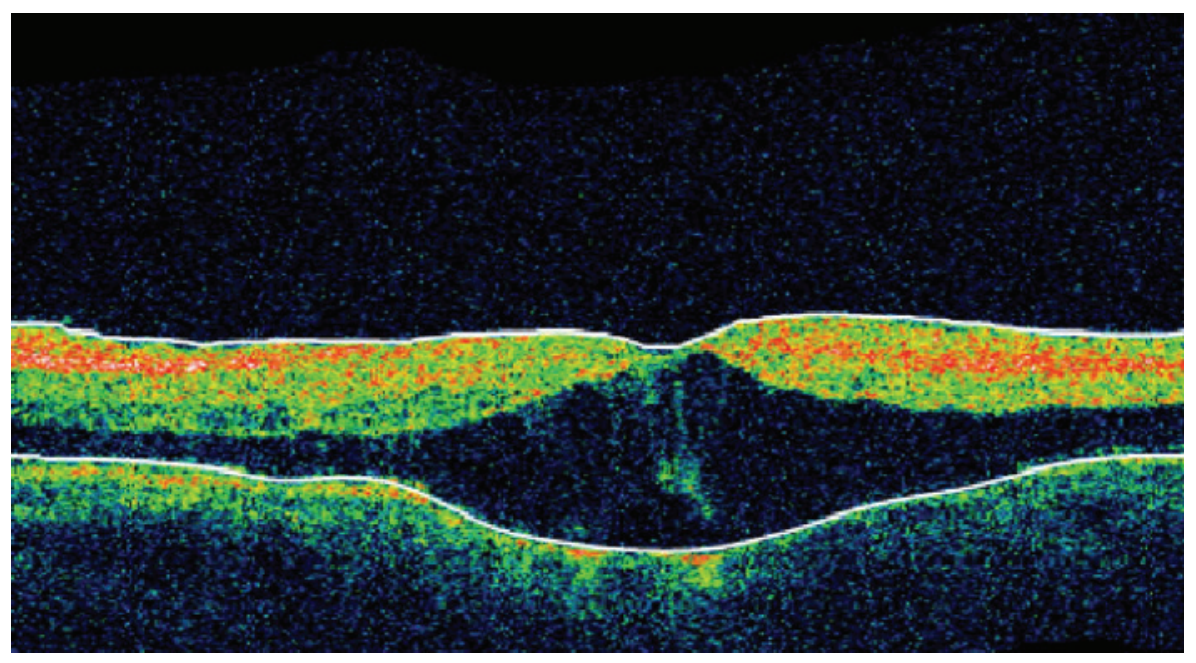

Fig. 2. OCT exhibited macular thickening $(626 \mu \mathrm{m})$ secondary to diffuse edema and presence of microcysts.

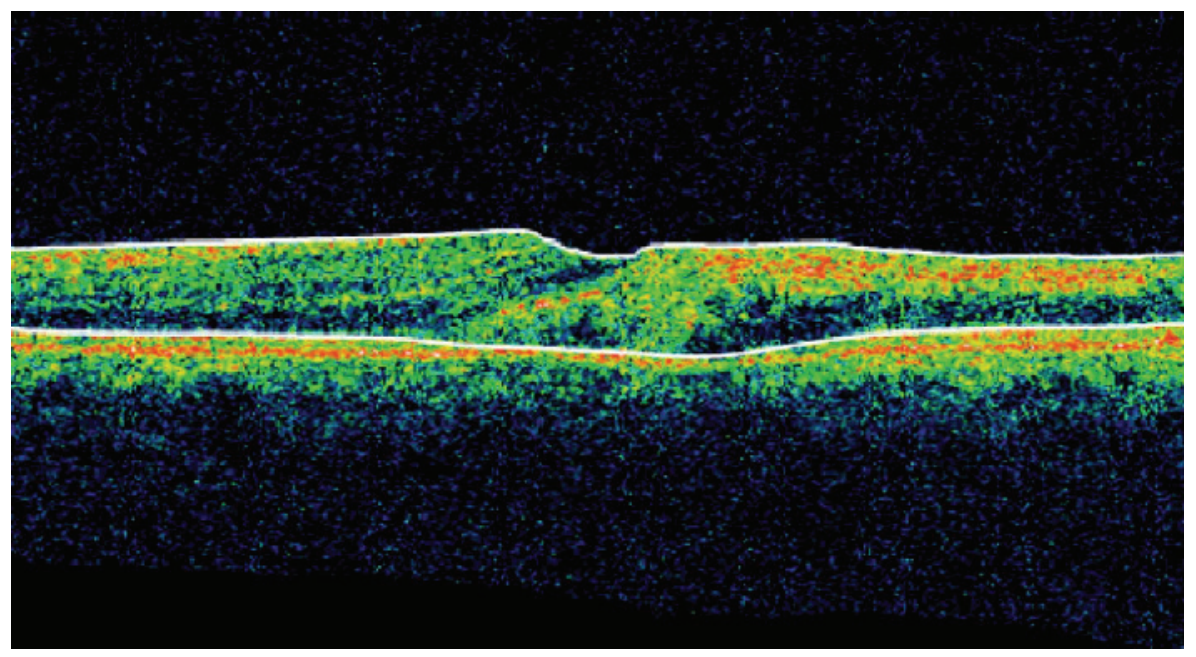

Fig. 3. OCT 2 months after the suspension of INF demonstrated decreased macular retinal thickness $(322 \mu \mathrm{m})$ and partial resolution of edema. 


\begin{tabular}{c|l|l|l}
$\begin{array}{c}\text { Case Reports in } \\
\text { Ophthalmology }\end{array}$ & $\begin{array}{l}\text { Case Rep Ophthalmol 2011;2:23-29 } \\
\text { DOI: 10.1159/000323942 }\end{array}$ & $\begin{array}{l}\text { Published online: } \\
\text { January 11, 2011 }\end{array}$ & $\begin{array}{l}\text { O 2011 S. Karger AG, Basel } \\
\text { ISSN 1663-2699 } \\
\text { www.karger.com/cop }\end{array}$ \\
\hline
\end{tabular}

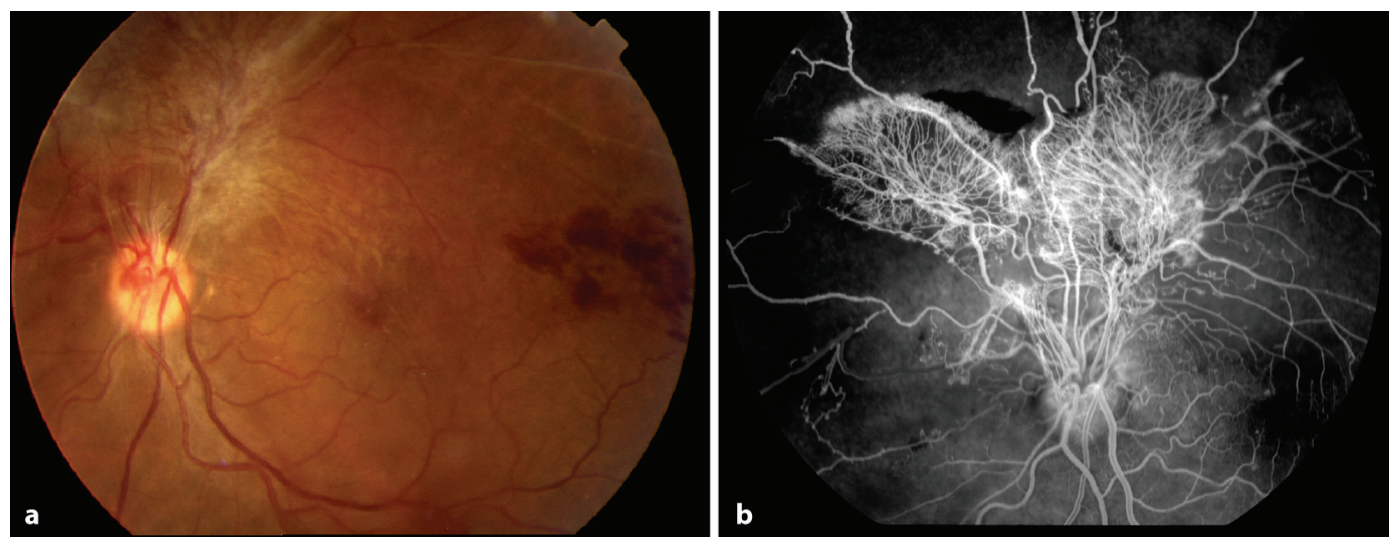

Fig. 4. Control 4-month angiographies revealed large areas without capillary perfusion in the upper quadrants, neovascularization, and diffuse macular edema.

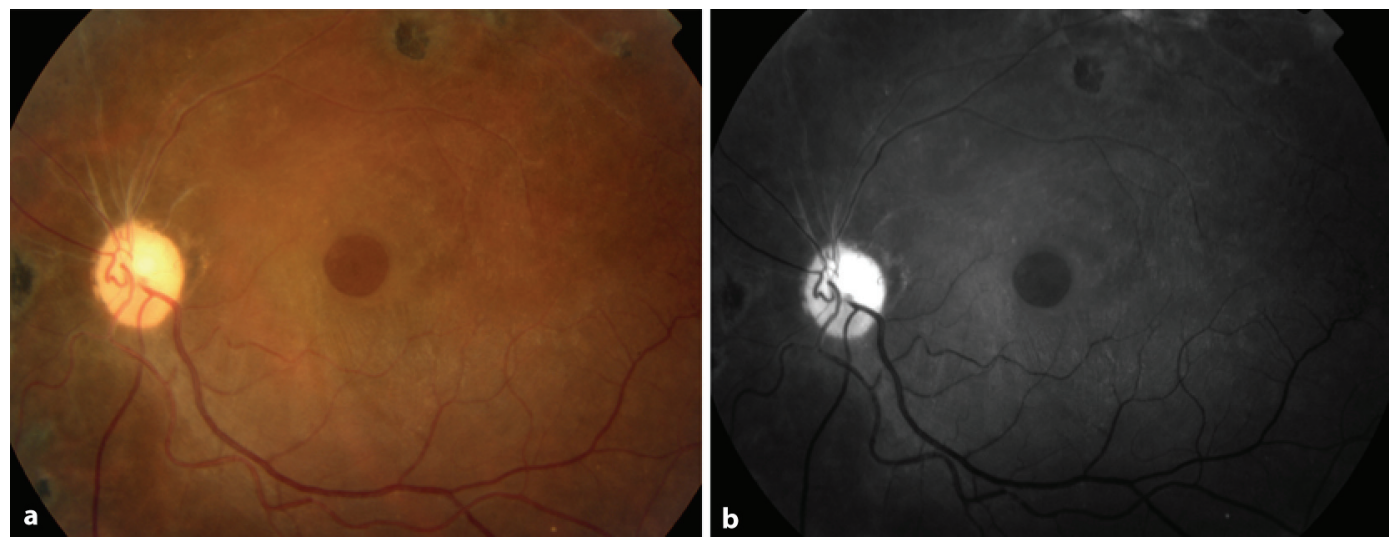

Fig. 5. After 3 years of follow-up, fundoscopy revealed optic disc pallor, superior retinal atrophy, and macular hole. 


\section{References}

1 WHO: Hepatitis C: global prevalence. Wkly Epidemiol Rec 2002;77:6.

2 Okuse C, Yotsuyanagi H, Nagase Y, et al: Risk factors for retinopathy as associated with interferon alpha-2b and ribavirin combination therapy in patients with chronic hepatitis C. J Gastroenterol 2006;12:3756-3759.

-3 Cuthbertson FM, Davies M, McKibbin M: Is screening for interferon retinopathy in hepatitis C justified? Br J Ophthalmol 2004;88:1518-1520.

4 Jain K, Lam WC, Waheeb S, Thai Q, Heathcote J: Retinopathy in chronic hepatitis C patients during interferon treatment with ribavirin. Br J Ophthalmol 2001;85:1171-1173.

5 Sène D, Touitou V, Bodaghi B, et al: Intraocular complications of INF- $\alpha$ and ribavirin therapy in patients with chronic viral hepatitis C. World J Gastroenterol 2007;13:3137-3140.

6 Mantel I, Konstantinidis L, Zografos L: Interferon-associated retinopathy. A Case Report. Klin Monatsbl Augenheilkd 2007;224:350-352.

7 Andrade R, González J, Vázquez L, et al: Vascular ophthalmological side effects associated with antiviral therapy for chronic hepatitis $\mathrm{C}$ are related to vascular endothelial growth factor levels. Antivir Ther 2006;11:491-498.

$>8$ Schmidt S, Pleyer U: Interferon- $\alpha$ assoziierte Retinopathie bei Patienten mit chronischer Hepatitis C. Klin Monatsbl Augenheilkd 2005;22:915-918.

9 Stoffelns B: Interferon löst okuläre Ischämien aus. Fallserie und Literaturüberblick. Klin Monatsbl Augenheilkd 2006;223:467-371.

10 Francis J, Ho I, Yannuzzi L: Vitreous hemorrhage associated with interferon-a therapy for chronic hepatitis C. Retinal Cases and Brief Reports 2008;2:262-263.

11 Martínez H, Pulido J, Haupert C, et al: Interferon- $\alpha$ associated retinopathy. Retinal Cases and Brief Reports 2009;3:24-26

12 Gunther J, Altaweel M: Bevacizumab (Avastin) for the treatment of ocular disease. Surv Ophthalmol 2009;54:372-400

13 Krupinski J, Kaluza J, Kumar P, Kumar S, Wang JM: Role of angiogenesis in patients with cerebral ischemic stroke. Stroke 1994;25:1794-1798. 